\title{
EXTENSÃO UNIVERSITÁRIA: O IMPACTO DE UM PROJETO DE EXTENSÃO NA FORMAÇÃO PROFISSIONAL DOS DISCENTES NA EDUCAÇÃO SUPERIOR
}

\author{
Carolina Andréa Soto Canon ${ }^{1}$ \\ ORCID: 0000-0001-8537-3333
}

\author{
Gisela Pelegrinelli ${ }^{2}$ \\ ORCID: 0000-0001-8537-3890
}

Resumo: O objetivo desta pesquisa foi analisar qual o impacto de um projeto de Extensão na formação profissional dos discentes numa Instituição de Educação Superior Privada do Distrito Federal. O projeto do Núcleo de Práticas Jurídicas, "Van Cidadâ" do curso de Direito e Serviço Social, é uma unidade móvel de atendimento que visita as comunidades carentes de todo o Distrito Federal levando cidadania, informação, conhecimento, orientação e assistência jurídica gratuita. Para analisar a percepção dos participantes de um projeto de extensão, foi elaborado um questionário com questões relacionadas ao significado e a relevância de exercitar a extensão na vida acadêmica e para a formação profissional. A análise obtida no trabalho aponta que a grande maioria dos entrevistados diz saber o que é um projeto de extensão universitária ou ação extensionista. Da mesma forma, os discentes têm ciência que são

1 Especializada em Gestão de Processos Acadêmicos pelo Centro Universitário Projeção - UniProjeção (2018). Graduanda em Tecnólogo em Gestão de Recursos Humanos pelo Centro Universitário UniProjeção modalidade à distância (2017). Bacharelado em Administração de Empresas pela faculdade Projeção (2015). E-mail: (carolina.canon@projecao.br).

2 Doutoranda em Ciências Sociais pela UNISINOS. Possui Mestrado em Ciências Sociais pela UNISINOS, Bacharelado em Administração pela Universidade Católica de Brasília (2016), Licenciatura em Educação Física pela Universidade Católica de Brasília (1987). Especialização em Gestão de Processos Acadêmicos pelo Centro Universitário Projeção - UniProjeção (2013) e Pesquisa em Docência em Turismo pela UnB (2003). E-mail: (gisela.intercult@gmail.com). 
aplicados projetos de extensão universitária na Instituição onde estudam. Contudo, ainda há uma minoria dos participantes da pesquisa que relatam dúvidas quanto ao projeto de extensão oportunizar ao acadêmico a prestação de serviços à comunidade e também a preparação para o mercado de trabalho. $\mathrm{O}$ atendimento ao público foi a maior contribuição na formação profissional segundo os entrevistados, pois é possível adquirir experiência e despertar novos estudos para o desenvolvimento do trabalho em equipe. Por fim, foi possível observar que os participantes indicariam o Projeto Van Cidadã para os alunos do próximo semestre.

Palavras-chave: Extensão Universitária; Projetos de Extensão; Formação profissional.

Abstract: The objective of this research was to analyze the impact of an extension project on the professional formation of students in a Private Higher Education Institution of the Federal District. The course of the Legal Practice Center, "Van Cidadã", of the Law course and social service, is a mobile service unit that visits the needy communities of the entire Federal District that conducts citizenship, information, knowledge, guidance and free legal education. In order to obtain a perception of the participants of an extension project, a questionnaire was elaborated based on the significance and an extension of exercise in the academic life and for a professional formation. The analysis obtained in the study points out that the great majority of respondents say they know what a university extension project or extensionist action is. In the same way, the students are aware that university extension projects are applied in the Institution where they study. However, there is still a minority of the research participants who report doubts about the extension project to provide the academic community with services and preparation for the job market. The service to the public was the greatest contribution in professional training according to the interviewees, because it is possible to gain experience and stimulate new studies for the development of teamwork. Finally, it was possible to observe that the participants would indicate the Van Citizen Project for the students of the next semester.

Keywords: University Extension; Extension Projects; Professional Training

Resumen: El objetivo de esta investigación fue analizar el impacto de un proyecto de Extensión en la formación profesional de estudiantes en una institución privada de educación superior del Distrito Federal. El proyecto del Centro de Práctica Jurídica "Van Cidadâ" del curso de Derecho y Trabajo Social es una unidad de servicio móvil que visita comunidades desatendidas en todo el Distrito Federal, brindando ciudadanía, información, conocimiento, orientación y asistencia legal gratuita. Para analizar la percepción de los participantes de un proyecto de extensión, se elaboró un cuestionario con preguntas relacionadas con el significado y la relevancia de ejercer la extensión en la vida académica y para la formación profesional. El análisis obtenido muestra que la gran mayoría de los encuestados dicen que saben qué es un proyecto de extensión universitaria o una acción de extensión. Del mismo modo, los estudiantes son conscientes de que los proyectos de extensión universitaria se aplican en la institución donde estudian. Sin embargo, todavía hay una minoría de participantes en la encuesta que informan dudas sobre el proyecto de extensión para brindar al académico la oportunidad de brindar servicios a la comunidad y también prepararse para el mercado laboral. La asistencia al público fue la mayor contribución a la formación profesional según los entrevistados, ya que es posible adquirir experiencia y 
despertar nuevos estudios para el desarrollo del trabajo en equipo. Finalmente, se observó que los participantes nominarían el Proyecto "Van Cidadâ" para estudiantes en el siguiente semestre. Palabras clave: Extensión universitaria; Proyectos de extensión; Entrenamiento profesional. Submetido em: 15/05/2019.

Aceito em: 01/08/2019.

\section{INTRODUÇÃO}

Ensino, pesquisa e extensão constituem as três funções básicas da Universidade, as quais devem ser equivalentes e merecer igualdade em tratamento por parte das instituições de ensino superior, pois, ao contrário, estarão violando esse preceito constitucional (SILVA,1996).

A pesquisa foi desenvolvida com o enfoque no impacto de um projeto de extensão sob o olhar dos discentes do curso de Direito enquanto sua formação profissional. Nesse sentido, tem-se o seguinte problema da pesquisa: De que forma os projetos extensionistas podem impactar na formação profissional do discente?

A partir da problemática, o objetivo geral deste artigo é analisar o impacto de um projeto de extensão na formação profissional do discente numa Instituição de Educação Superior no Distrito Federal. Os objetivos específicos incluem: caracterizar a Extensão Universitária, mapear a percepção dos discentes sobre o projeto "Van Cidadã" e discutir os impactos do projeto na formação profissional dos estudantes.

Segundo o Plano Nacional de Extensão, publicado em 1999, a extensão universitária é o processo educativo, cultural e científico que articula o ensino e a pesquisa de forma indissociável e viabiliza a relação transformadora entre a universidade e a sociedade (EXTENSÃO UNIVERSITÁRIA, 2007).

Esse estudo se justifica pelo fato de que é relevante um projeto de extensão universitário no curriculum dos discentes, considerando que as atividades de extensão são fundamentais para complementar o desenvolvimento da formação profissional, uma vez que teoria e prática andam juntas.

Tanto para a sociedade como para os estudantes a extensão é uma constante prática de ensino. Isto se evidencia quando se afirma que a extensão é um processo de mão dupla: se ensina e se aprende ao mesmo tempo. Um exemplo claro disto é quando se faz extensão em uma comunidade - os estudantes ensinam algo para eles e eles ensinam algo para os estudantes. Esta troca de saberes se dá através do ensino. (BIONDI, ALVES 2011) 
A estrutura do presente trabalho está apresentada em quatro seções: A primeira é a fundamentação teórica, que aborda um breve estudo sobre a extensão universitária, apresenta o conceito, a importância e sua evolução. Nesta seção também serão apresentados aspectos importantes acerca da extensão e sua relevância na formação profissional. A segunda seção descreve a metodologia do trabalho. No terceiro momento são analisados os resultados e discussões dos dados coletados e a quarta e última seção trata das conclusões do presente estudo.

\section{REFERENCIAL TEÓRICO}

Apresenta-se aqui o referencial teórico que serviu de base para o estudo bibliográfico, apresentando os seguintes temas: Evolução da Extensão Universitária, A extensão universitária e a formação profissional.

\section{EVOLUÇÃO DA EXTENSÃO UNIVERSITÁRIA}

A extensão universitária surgiu na Inglaterra em função da necessidade advinda da Revolução Industrial, e atrelada ao capitalismo. Embora neste momento a função da Universidade estivesse centrada na formação quase exclusivamente para a elite, e assumindo um papel de conhecimentos racionais para novos delineamentos da sociedade, existia a preocupação de levar informações através de cursos para as classes populares (RODRIGUES, 1997).

De acordo com SUGAHARA 2012: "Extensão universitária na Lei de Diretrizes e Bases da Educação Nacional no 9.394 de 1996 é considerada um processo educativo, cultural e científico que articula o Ensino e a Pesquisa de forma indissociável e viabiliza a relação transformadora entre Universidade e Sociedade.

Nessa colocação o autor revela que a extensão vai para além da universidade. Ao lado da pesquisa e do ensino ela tem a função de abrir as portas para a resolução de problemas da realidade.

A extensão universitária educativa seria então, ao lado do ensino e da pesquisa, uma das possibilidades para problematizar a realidade. Ao contrário do que pode parecer a extensão universitária “é uma via de mão-dupla, com trânsito assegurado à comunidade acadêmica, que encontrará, na sociedade, 166 Conexão UEPG - a oportunidade de elaboração das práxis de um conhecimento acadêmico" (BRASIL, LDB - LEI DE DIRETRIZES E BASES DA EDUCAÇÃO NACIONAL, 1996). 
Além de oportunizar aos acadêmicos um acréscimo de conhecimento, a extensão se estende para a população em geral, fazendo que a Instituição de ensino seja visada e reconhecida.

A percepção de tudo isso é indispensável à política que orienta Programas e Projetos de Extensão das Instituições de Ensino. Isso, necessariamente nos impõe o dever enquanto docentes e discentes de trazer um aprendizado que "submetido à reflexão teórica, será acrescido àquele conhecimento". Por sua vez, neste "processo dialético de teoria/prática, a Extensão é um trabalho interdisciplinar que favorece a visão integrada do social" (BRASIL, LDB - LEI DE DIRETRIZES E BASES DA EDUCAÇÃO NACIONAL, No 9.394, 1996).

\section{EXTENSÃO UNIVERSITÁRIA E A FORMAÇÃO PROFISSIONAL}

Segundo Oliveira e Garcia (2009) extensão, hoje, articula um processo educativo, cultural e científico, ao lado do ensino e da pesquisa, gerado pelas possibilidades e pela força articuladora que está na natureza das ações nascidas das relações sociais e comunitárias.

Conforme Prates, Viana e Landim (2017) a extensão é a possibilidade de que tanto o ensino quanto a pesquisa tenham como tema a sociedade e sua transformação, originando-se nela e para ela retornando. Em outras palavras, a extensão é a porta para que a universidade interaja com o meio social em que se insere. Cabe à extensão fazer esse cordão umbilical entre universidade e sociedade.

Durante a graduação os acadêmicos que participam de projetos de extensão possuem uma oportunidade a mais de inserção na realidade que encontrará quando tornar-se um profissional.

A extensão possibilita ao acadêmico a experiência do contato entre o aprendizado na Universidade e a aplicabilidade de sua profissão na sociedade, conhecendo a prática de sua profissão. (MANCHUR;SURIANI;CUNHA 2013).

Para Manchur, Suriani e Cunha (2013) parte-se do princípio de que a formação do acadêmico é tomada como fundamento do processo educativo implementado na universidade, uma vez que contribuirá para sua compreensão como ser socialmente responsável e livre, capaz de refletir sobre o vivido e o aprendido em sala de aula e outros espaços, como na comunidade, que vão construindo cotidianamente sua identidade pessoal e profissional alicerçadas na busca do saber ser, saber fazer e saber aprender, ou seja, na formação de suas competências. 
No retorno à universidade, docentes e discentes terão um aprendizado que submetido à reflexão teórica, seria acrescido àquele conhecimento. Este fluxo, que estabelece a troca de saberes sistematizados /acadêmico e popular, terá como consequência a mudança de conhecimento acadêmico e a participação efetiva da comunidade na atenção da universidade (FORUM, 2001).

A extensão universitária passa a ser integrante na dinâmica pedagógica do processo de formação acadêmica, expandindo a produção de conhecimento. Uma nova visão que permite o diálogo entre professores e alunos, oportunizando uma flexibilidade no currículo, e possibilitando ao aluno a obtenção de uma formação mais crítica e construtiva (JEZINE, 2004).

Quanto ao quesito de interação dialógica, o que se pretende buscar é o desenvolvimento de relações entre universidade e setores sociais marcadas pelo diálogo, pela ação de mão-dupla, de troca de saberes, de superação do discurso da hegemonia acadêmica - que ainda marca uma concepção ultrapassada de extensão: estender à sociedade o conhecimento acumulado pela universidade - para uma aliança com movimentos sociais de superação de desigualdades e de exclusão (NOGUEIRA, 2000)

\section{METODOLOGIA}

Esta seção tem como proposta central delinear a metodologia que norteou a pesquisa científica, caracterizada como bibliográfica, descritiva e qualitativa.

O presente estudo teve como objetivo analisar o impacto de um projeto de extensão na formação profissional do discente. Para tal, foi utilizada como etapa inicial a pesquisa bibliográfica. Para Cervo (2002) a pesquisa bibliográfica procura explicar um problema a partir de referências teóricas.

Galliano, (1979) afirma que a pesquisa bibliográfica é a que se faz tentando resolver um problema para se ter um novo conhecimento do que está sendo estudado através de informações vindas de livros, arquivos publicados e outros.

O delineamento se dá nos campos da pesquisa descritiva que de acordo com os autores Cervo e Bervian (2002) a pesquisa descritiva observa, registra, analisa e correlaciona fatos ou fenômenos (variáveis) sem manipulá-los.

Para Marconi e Lakatos (2017), abordagem qualitativa constitui-se de técnicas de pesquisa documental estruturadas ou semiestruturadas. Esse tipo de pesquisa busca descobrir as razões para determinados comportamentos, atitudes e motivações, em vez de se concentrar apenas nos detalhes "do que, onde e quando". 
Dando prosseguimento à pesquisa, o instrumento utilizado foi um questionário com 10 perguntas sendo 9 fechadas e uma aberta. Ressalta-se que o questionário foi aplicado para subsidiar respostas descritivas. Nesse caso o entrevistador não participa e nem interage com a situação proposta. Conforme afirmação de Marconi e Lakatos (2017) questionário é um instrumento de coleta de dados, constituído por uma série ordenada de perguntas, que devem ser respondidas por escrito e sem a presença do entrevistador. Em geral, o pesquisador disponibiliza o questionário ao informante in loco, pelo correio ou por um portador (Cervo e Bervian, 2002).

Os dados foram coletados em dois dias distintos no momento da ação do projeto do Núcleo de Práticas Jurídicas, realizado pela Escola de Ciências Jurídicas e Sociais, "Van cidadã", que é uma unidade móvel de atendimento que visita as comunidades carentes de todo o Distrito Federal levando cidadania, informação, conhecimento, orientação e assistência jurídica gratuita.

O referido projeto faz parte do curso de Direito e Serviço Social da Faculdade Projeção de Sobradinho e é composto pelos discentes que estão matriculados em estágio supervisionado, disciplina curricular obrigatória.

O objetivo da Van Cidadã é oportunizar a prática do voluntariado aos estagiários, formando cidadãos críticos e conscientes da responsabilidade social, ampliando experiências e oferecendo a eles a oportunidade de colocar em prática os conhecimentos adquiridos nos Cursos de supracitados, por meio da prestação jurídica à comunidade.

O Projeto é realizado na Região Administrativa de Sobradinho em média com três Vans Cidadãs por semestre. Ademais, são abertas 12 vagas em cada Van no sistema de registro acadêmico para os alunos devidamente matriculados na disciplina de Estágio Supervisionado. As Vans ficam alocadas na Feira Modelo de Sobradinho e, também em eventos, como o aniversário de Sobradinho, quando a Faculdade de Sobradinho é convidada.

$\mathrm{Na}$ Van os estagiários realizam o atendimento, que é supervisionado por um Advogado Orientador (curso de Direito) ou um assistente social (curso de Serviço Social), onde as dúvidas são esclarecidas. Assim, o assistido é encaminhado à um dos Núcleos de Práticas Jurídicas da Faculdade Projeção para o prosseguimento das atividades. No primeiro semestre de 2018 participaram da atividade 36 estagiários e no segundo semestre do mesmo ano participaram 30. Para efeito do presente trabalho, serão considerados os alunos do último semestre de 2018, ou seja, 2018/2. 
Algumas vantagens da importância da coleta de dados de acordo com Barros (2000) são socializar o conhecimento obtido durante o processo de pesquisa científica, isto é, apresentar sistematicamente os resultados do estudo à comunidade científica, às instituições de pesquisa, aos sujeitos envolvido e à sociedade.

Nos dias coletados, a "Van Cidadã" estava realizando atendimento na Feira Modelo em Sobradinho I, Região Administrativa do Distrito Federal. Foram distribuídos 30 questionários com 9 perguntas fechadas e uma aberta, em dois dias distintos.

A devolutiva do questionário totalizou 28 respondentes sendo que o objetivo e a proposta da pesquisa foram expostos aos discentes de forma clara e sem questionamentos.

\section{RESULTADOS E DISCUSSÕES}

Como relata Barros (2000) a codificação transforma os dados em elementos quantificáveis e qualificáveis descritivos. Para este trabalho foi utilizado o processo pelo qual se apresentam os dados obtidos da categorização de forma descritiva acerca dos objetivos propostos.

A disposição dos dados graficamente auxilia a interpretação da análise e facilita o processo de inter-relação entre eles e da relação deles com a problemática do estudo. Com os resultados obtidos na análise dos dados foram organizados os seguintes tópicos: Conhecimento sobre Extensão Universitária; Projetos de extensão na Instituição de Ensino; as oportunidades em um projeto de Extensão Universitária; Motivos da participação no projeto de Extensão "Van Cidadâ".

A primeira pergunta resultou em 100\% dos respondentes serem alunos do curso de Direito, visto que naquele semestre não havia alunos matriculados em estágio do curso de Serviço Social.

Quanto à segunda pergunta, todos os respondentes (100\%) estavam matriculados na disciplina de Estágio Supervisionado.

Na terceira pergunta, sobre a orientação do professor de estágio, 80\% responderam que sim, o professor orientou acerca das atividades. Todavia, 20\% responderam que não sabiam. Abaixo os resultados em gráficos com as interpretações acerca dos objetivos propostos: 


\section{PERGUNTAS FECHADAS}

CONHECIMENTO SOBRE ExtensÃo UNIVERSITÁRIA - GrÁFICO 1

1) Você sabe o que é Extensão Universitária ou Ações Extensionistas?

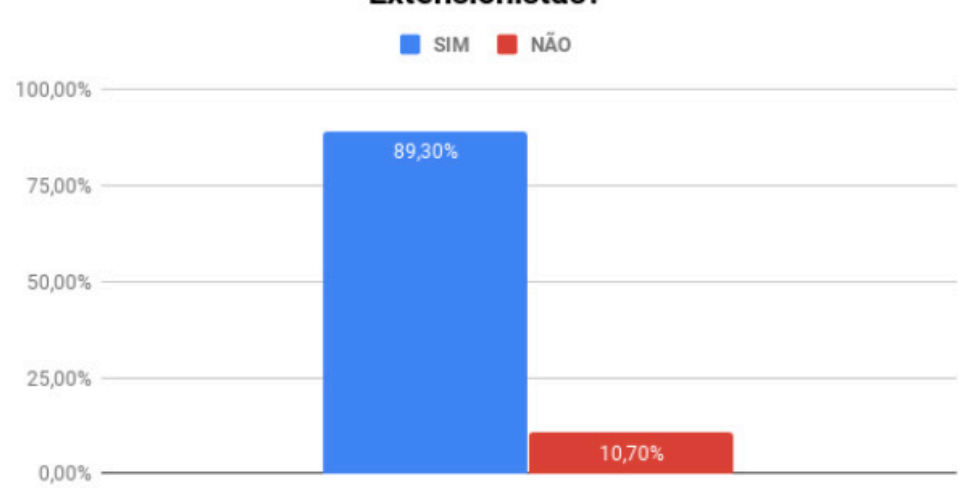

Fonte: ELABORADO PELAS AUtORAS (2019)

Como relata Barros (2000) a codificação transforma os dados em elementos quantificáveis e qualificáveis descritivos. Para este trabalho foi utilizado o processo pelo qual se apresentam os dados obtidos da categorização de forma descritiva acerca dos objetivos propostos.

ConheCIMENTO SOBRE EXTENSÃo UNIVERSitÁRIA-GráFICO 1

2) A Instituição onde você estuda realiza projetos de Extensão?

- SIM NÄO NA VERDADE, NÄO SEI

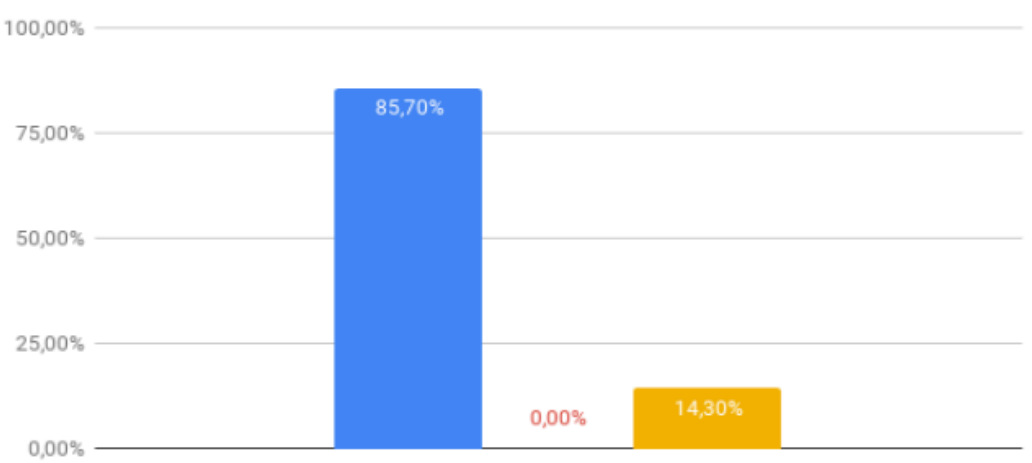

Fonte: ELABORADO PELAS AUtORAS (2019) 
O gráfico 2 demonstra que a maioria $(85,7 \%)$ dos entrevistados diz saber sobre a realização de projetos de extensão na Instituição onde estuda. $\mathrm{O}$ restante dos estudantes (14,3\%) na verdade não sabe se há ou não algum projeto de extensão na sua Instituição de ensino. As dúvidas ainda surgiram em função de alguns alunos desconhecerem a expressão "ações extensionistas".

As oportunidades de um Projeto de Extensão UnIVERSITÁRIA- GrÁfICO 3

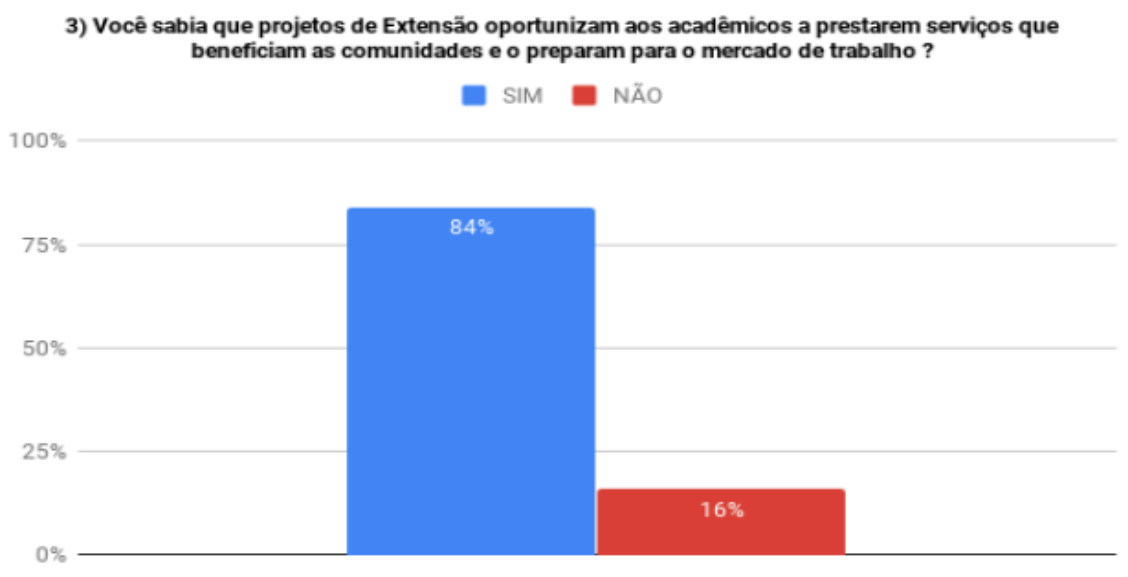

Fonte: ELABORADO PELAS AUTORAS (2019)

O gráfico 3 representa o percentual dos alunos que possuem conhecimento em relação as oportunidades de um projeto de extensão para os alunos e os preparam para o mercado de trabalho. Nota-se que a maioria com $84 \%$ tem ciência e 16\% não tem. Este resultado comprova a preocupação da IES ao realizar a extensão universitária reconhecendo-a como um instrumento essencial para criação de estratégias de aproximação junto à sociedade, oportunizando o conhecimento da realidade, como também a aplicação de técnicas pertencentes à sua profissão.

O gráfico 4, a seguir, representa o percentual do motivo que levou o estudante a participar do projeto de Extensão "Van Cidadã". Dentre o total, 28\% respondeu que o motivo foi estágio não obrigatório, 52\% crescimento profissional, 20\% curiosidade. Importante neste contexto profissional, foi a comprovação dos discentes ao procurar o projeto. Por meio dele, os acadêmicos aproximam-se da sociedade e têm a oportunidade de vivenciar a aplicação de conhecimentos de sua futura profissão, podendo, assim, identificar aspectos 
que precisam ser aperfeiçoados para ampliar sua competência profissional. As oportunidades de um Projeto de Extensão Universitária- Gráfico 3

Motivos da Participação no Projeto de Extensão “Van Cidadã”- Gráfico 4

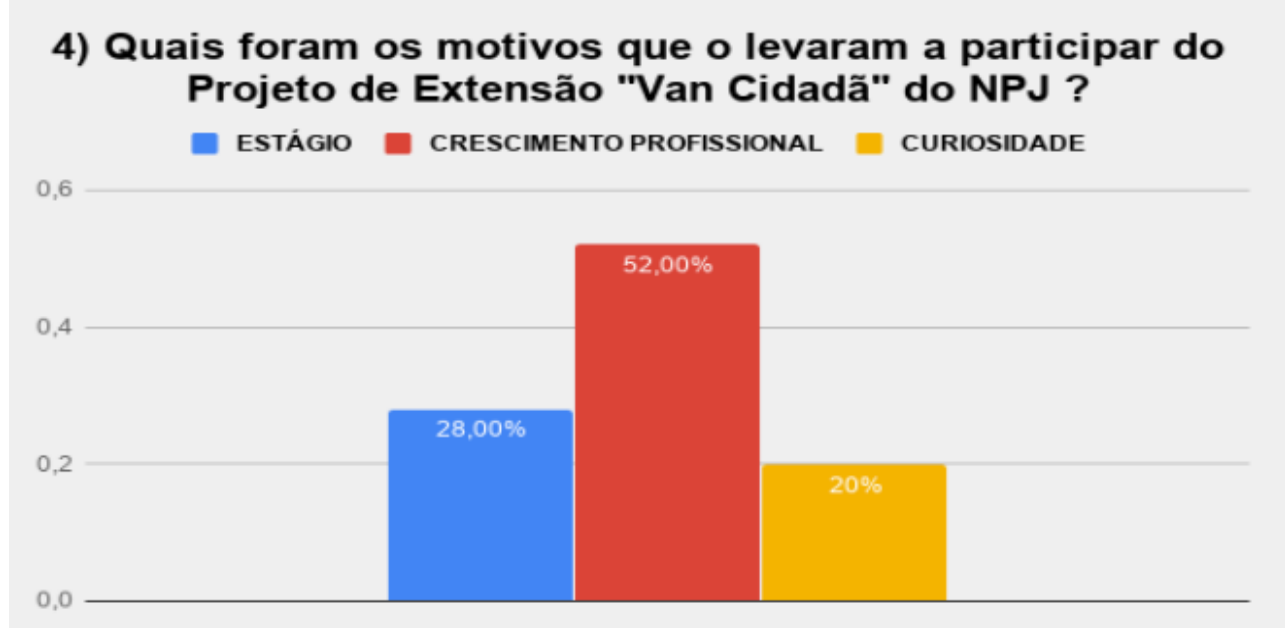

Fonte: ELABORADO PELAS AUtORAS (2019).

ApLICABILIDADE DO CONHECIMENTO ADQUIRIDO-CRÁFICO 5

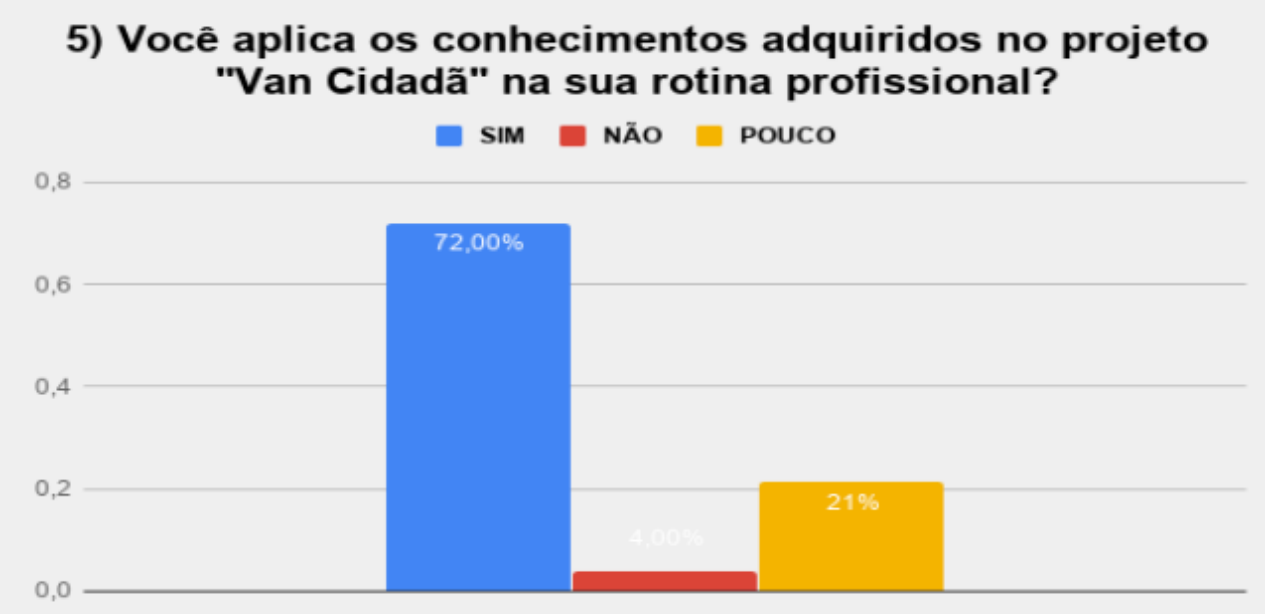

Fonte: ELABORADO PELAS AUTORAS (2019). 
Foi mensurado através do questionário se o aluno aplica o conhecimento adquirido no projeto "Van Cidadâ" em sua rotina profissional e constatou-se que $72 \%$ aplica, 3,6\% não aplica e $21 \%$ pouco aplica.

Nesta perspectiva, muito tem se falado e debatido acerca da necessidade de diminuir a distância entre a academia e a comunidade visando práticas e saberes no cotidiano profissional. Ademais, é preciso oportunizar a formação profissional, ponto de partida não apenas no âmbito de técnicas e habilidades, sobretudo, é pertinente que os alunos se reconheçam como sujeitos de direito e de transformação social.

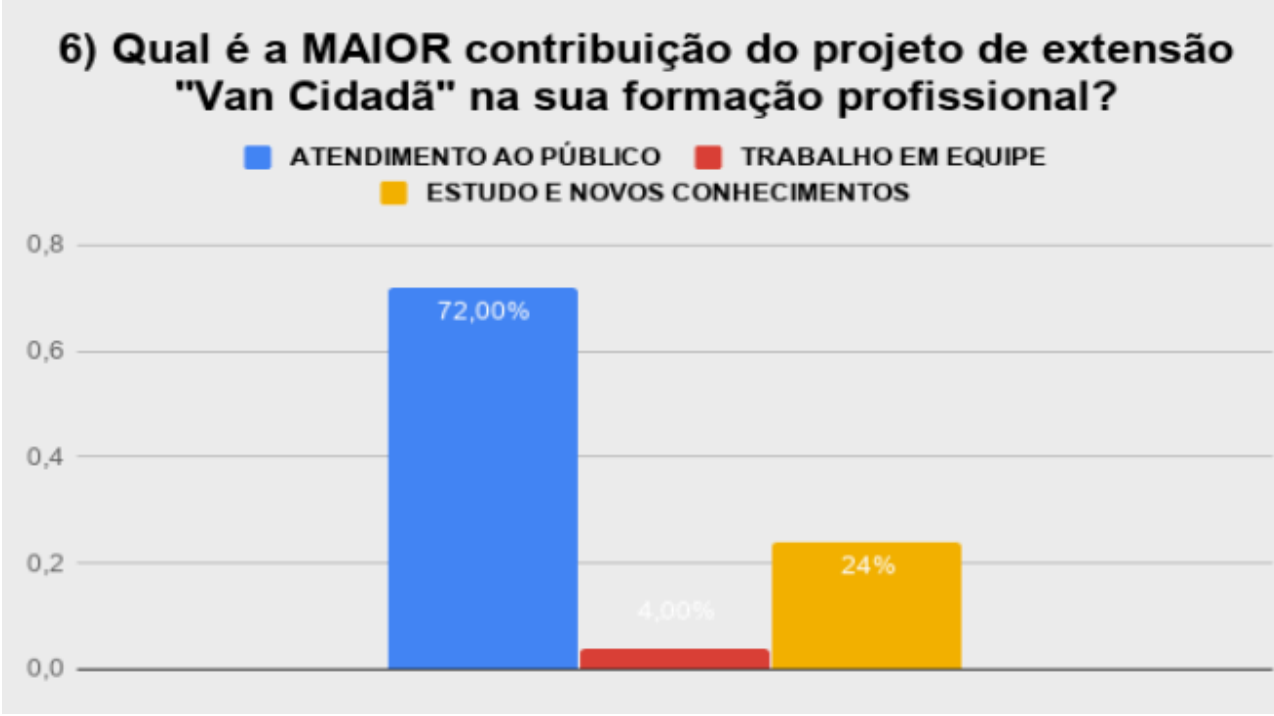

Fonte: ELABORADO PELAS AUTORAS (2019).

O gráfico 6 por fim, revelou que a maior contribuição do projeto na formação profissional foi de desenvolver o atendimento ao público com $72 \%$, desperta o trabalho em equipe com $4 \%$, desperta estudo e novos conhecimentos (24\%).

Nesta questão, é importante observar que a interação com a comunidade traz diversos pontos positivos para o desenvolvimento profissional dos alunos do projeto "Van Cidadâ", a saber: melhor desenvoltura para atender e falar em público, as relações interpessoais, a capacidade de compartilhar conhecimentos já adquiridos, dentre outros.

A extensão é um caminho de mão dupla: a instituição leva o conhecimento produzido dentro dela para o público externo e, dessa interação, também aprende com os grupos sociais envolvidos. A prática é, sem dúvida, grande aliada do crescimento e formação profissional do discente. 


\section{PERGUNTA ABERTA: RECOMENDARIA O REFERIDO PROJETO A OUTROS ALUNOS? PORQUE?}

Dentre os 28 participantes, apenas 9 responderam. Abaixo as respostas identificadas por R1 até R9:

R1: "Com certeza. O caráter mais prático das disciplinas funciona para enriquecer o currículo de quem participa e serve de base para eventualmente conseguir uma vaga de estágio ou um cargo efetivo que necessita de experiência".

R2: “Sim. Para quem procura uma forma de se aperfeiçoar na graduação, os projetos de extensão podem servir de laboratório e até mesmo de escada para a criação de um currículo acadêmico aprofundado dentro da área. Estou bem satisfeito com o Projeto Van Cidadâ".

R3: "Sim. Para adquirir ainda mais conhecimento pela área de formação antes, durante ou após a graduação, uma das possibilidades é optar por projetos de extensão, como o Van Cidadã".

R4: "Claro! Os projetos de extensão representam uma opção de aprendizado para que nós, alunos, acompanhe as tendências do mercado de trabalho".

R5: "Sim. Com o projeto van cidadã, a gente aprende conceitos relacionados às áreas escolhidas e desenvolvemos habilidades específicas em nossa área (ou áreas) de atuação".

R6: "Recomendaria. Os projetos como o do Van Cidadã são voltados para diversas áreas e possuem inúmeros benefícios para o estudante que deseja obter maior aprendizado".

R7: "Sim. As exigências do mercado de trabalho não se restringem ao conhecimento vivenciado em sala de aula. Projetos de extensão são úteis ao garantir maior aprendizado prático em diversas áreas, fator importante para crescimento na carreira".

R8: "Recomendaria. Com o projeto Van cidadã a gente pode aplicar aquilo que viu durante a aula e aprender na prática aqueles conteúdos que até então eram só teoria. Ou seja: todo aquele conhecimento de sala de aula pode ficar bem concreto".

R9: "Sim. Quando a gente coloca em prática algum conhecimento, fica até mais fácil de entender as origens daquele conteúdo. No caso do projeto Van cidadã, o melhor de tudo é que com a compreensão expandida de um assunto, a gente consegue ir além do pensamento comum". 


\section{CONCLUSÃO}

A extensão universitária permite uma maior aproximação entre a Universidade e a comunidade, colaborando para uma educação de qualidade, a qual é possibilitada durante a formação acadêmica. Entende-se que por meio de ações e projetos de extensão, as Instituições de ensino têm a oportunidade de levar até a comunidade os conhecimentos adquiridos e obter familiaridade com a pesquisa e o ensino.

No presente estudo, ficou evidenciado que os estudantes participantes do projeto "Van Cidadâ" entendem o que é extensão universitária e sua importância no desenvolvimento pessoal e profissional.

Assim, os resultados desta pesquisa corroboram com as delimitações teóricas aqui apresentadas, que é demonstrar o impacto das atividades de extensão na vida do acadêmico e sua contribuição para a formação profissional, sendo essa uma possiblidade de contextualizar a profissão e de interagir numa troca dialógica com a comunidade para a construção de novos conhecimentos nas Universidades.

Conforme dados levantados, a grande maioria dos discentes buscam acrescentar conhecimento à formação profissional e, consequentemente, melhorar sua atuação no atendimento ao público.

Por fim, foi evidenciado que a formação destes estudantes do projeto permitiu uma visão mais integral acerca da postura profissional universalizada e voltada para a realidade social onde os sujeitos estão inseridos, pelo motivo de que o sucesso de um bom profissional não depende apenas de sua competência profissional, e sim de outros fatores que podem ser transmitidos a partir da extensão universitária.

Recomenda-se que se apliquem mais pesquisas sobre os projetos de extensão universitária para enaltecer o papel de contribuição da extensão na vida acadêmica. Para trabalhos futuros, sugere-se averiguar a percepção dos alunos do Centro Universitário Projeção Campus I que também realiza o mesmo projeto "Van Cidadâ” no curso de direito da referida instituição.

\section{REFERÊNCIAS}

BIONDI, ALVES, A Extensão Universitária Na Formação De Estudantes Do Curso De Engenharia Florestal - Ufpr Rev. eletrônica Mestr. Educ. Ambient. ISSN 1517-1256, v. 26, janeiro a junho de 2011. Disponível em: https://periodicos.furg.br/remea/article/ view/3357. Acesso em 14 dez. 2018. 
CERVO, Amado Luiz. Metodologia cientifica. 5. Ed. São Paulo: Prentice Hall, 2002.

FÓRUM DE PRÓ-REITORES DE EXTENSÃO DAS UNIVERSIDADES PÚBLICAS BRASILEIRAS. Plano Nacional de Extensão (1999-2001). Brasília. SESU/MEC, 1999.

GALLIANO,A. Guilherme. O método científico: Teoria e Prática. São Paulo: Harbra, 1986.

JEZINE, E. As Práticas Curriculares e a Extensão Universitária. In: CONGRESSO BRASILEIRO DE EXTENSÃO UNIVERSITÁRIA, 2, 2004, Belo Horizonte. Anais... Belo Horizonte: UFMG, 2004. Disponível em: https://www.ufmg.br/congrext/Gestao/Gestao12. pdf. Acesso em: 18 jan.2014.

LAKATOS, E. M.; MARCONI, M.A. Técnicas de pesquisa: planejamento, execução de pesquisas, amostragens e técnicas de pesquisa, elaboração, análise e interpretação de dados. 7 ed. São Paulo: Atlas, 2010.

MANCHUR, J.; SURIANI, A. L. A; CUNHA, M. C. A contribuição de projetos de extensão na formação profissional de graduandos de licenciaturas. Revista Conexão - UEPG, volume 9, nº 02 - Jul/dez 2013. Disponível em: http:// www.revistas2.uepg.br/index.php/ conexao. Acesso em 07/01/2019

NOGUEIRA. Maria das Dores Pimentel. (Org.). Extensão Universitária. Diretrizes conceituais e políticas. Documentos básicos do Fórum Nacional de Pró-Reitores de Extensão das Universidades Públicas Brasileiras 1987 - 2000. Belo Horizonte: PROEXT/ UFMG/Fórum, 2000.

Oliveira, T. M., \& Garcia, B. R. A extensão e seu papel na formação acadêmica. Revista Univali, 14(1), 2009, p. 111-117.

RODRIGUES, M. M. Extensão Universitária: um texto em Questão. Rev. Educação e Filosofia, vol. 11, n. 21/22, p. 89-126, jan./jun. e jul./dez. 1997. Disponível em: http://www. seer.ufu.br/index.php/EducacaoFilosofia/ article/view/888/805. Acesso em: 02 jan. 2019.

SUGAHARA, Cibele Roberta. Revista Conexão UEPG, ISSN-e 2238-7315, Vol.8, №.2, 2012, págs. 164-169. Disponível em: http://revista.uemg.br/index.php/malestar/article/ view/60/89. Acesso em: 17 jan 2019. 